\title{
Correlation Study between Performances in Mathematics and Accounting Subjects among Undergratuates Students in the Nigerian Tertiary Institutions.
}

\author{
Onuoha Ijeoma Perpetua \\ Department of Business Education Ebonyi State College Of Education, Ikwo, Nigeria.
}

\begin{abstract}
This study was undertaken basically to find out if students that possess little or no background knowledge in mathematics can comfortably pursue a degree course in Accountancy. A sample of 40 students were selected randomly from each year in Accountancy Department of the University of Nigeria Nsukka (10 students from year one, year two, year three and final year). Tests of knowledge in each of the subjects were administered at each level and the reliability of 0.83 and 0.93 respectively was recorded. Correlation coefficient was used to determine the relationship between student's performances in the two subject areas. Investigation showed that there was no significant relationship between the test performances in mathematics and Accounting $P$ (>.05). From the findings made so far, students with little or no background knowledge in mathematics can comfortably pursue a degree course in Accountancy at the tertiary level.
\end{abstract}

Key words: Accounting, Coefficient, Correlation, Mathematics, Performances,

\section{Introduction}

There has been a wrong assertion that only students who are exceptionally brilliant and gifted in mathematics could undertake courses that involves calculations and mental coordination such as mathematics, Accounting, Economics, quantitative techniques, financial management, statistics etc. No wonder mathematics is a sine qua non to gaining admission to such courses in our institutions of higher learning.

Mathematics is one of the most highly required subjects for gaining admission into virtually all the education programs in our institutions. It has been and will continue to be a prerequisite for gaining admission into all the departments in our institutions of higher learning, which Accounting is one of them. A student who credited virtually all other subjects and failed mathematics in Senior Secondary Certificate Examination (SSCE) which is a minimum examination requirement for gaining admissions into the Nigerian Tertiary institutions, will continue to register for a re-sit until mathematics is credited. This has given credence to the misconception that better performance in mathematics leads to a better performance in Accounting; while poor performance in mathematics leads to poor performance in Accounting.

It is pertinent to note however that, there is no scientific evidence to support or dispute the claim that only exceptionally brilliant students who are well grounded in mathematics can undertake a degree program in Accountancy and other courses that involves high level calculations.

Efforts has been made by the Federal and State government in revising its National policy on education to include a good and modified education policy which will help the undergraduates to achieve self reliance and independence after graduation. Vocational and Business Education which Accounting is one of the core subject areas has been accorded a befitting recognition by the government at the various institutions governing bodies through the establishment and accreditation of these areas of study in our institutions of higher learning. The knowledge and skill gathered after successfully completing a degree program will help make the graduate self reliant and independent, which is one of the goals of National Policy in Education.

The impression that only exceptionally brilliant students who have background knowledge in mathematics can undertake a degree course in Accounting, has discouraged the prospective students from enrolling into the department of Accounting to pursue a degree course. This notion has lured many prospective students to go for other courses which according to them involve little or no calculations. This uninformed decision can likely lead to dissatisfaction and under achievement since they will be lured to pursue other courses which are contrary to what they desired in life, (Sambo, 2005).

The knowledge gathered after successfully pursuing a degree course in Accounting does not only make the graduate self reliant but also a renowned entrepreneur who is a boss of his own and who employs labour through the establishment of a Small and Medium Scale Enterprises (SME'S). Osuala (2004) and Amaewule (2003) have confirmed that these small scale businesses play a crucial role in the operations of the nation's economy. The entrepreneur according to Nzelibe (2006), are men and women of action, individualists and opportunists who possesses the power to take risks. An entrepreneur as a risk taking organizer of production inculcates and carries out the job of an accountant. An Accountant possesses every quality of an entrepreneur and therefore a risk bearer and the potential owner of a Small and Medium Scale Enterprise (SME). 
Entrepreneurship education is all about making graduates to be job producers rather than job seekers. Oborah (2006) while citing Osuala (2004) remarked that entrepreneurship education is a specialized training given to students to acquire the skills, ideas, and management abilities necessary for self reliance. Entrepreneurship education aims at inculcating in the students' knowledge, skill and attitudes which will help them in their studies or later in their circular life. It helps students experience various aspects of business ownership while understanding the basis of the economy, career opportunities that result and the need to master skills that will help them to be successful in a free market economy. To make the education system more relevant and responsive to the socio-economic problems generated by the teeming unemployment problems, entrepreneurship education should therefore be emphasized in the system. Nwaobuna (2004) is of the view that entrepreneurship education is the identification of the general characteristics of the entrepreneurs and how potential entrepreneurs can be trained in the management technique needed for effective performance of persons for long time survival of an organization.

\section{Methodology}

Random sampling technique was adopted to select 40 students out of the overall of population of Accountancy students from year one to final year, (10 students each from first year to final year). A test for Mathematics which had 0.83 reliability and a test for Accounting which had 0.93 reliability were constructed and administered. Each test was scored out of a maximum of 20 marks. The students represent the correlation coefficient which was used to determine the relationship between the test performances of Mathematics and Accounting respectively.

\section{Research Question} Accounting?

Can students with little or no background knowledge in Mathematics pursue a degree course in

Hypotheses Accounting.

Ho: There is no significant relationship between performances in Mathematics and performance in

\section{Analysis of Data Used}

Correlations for the scores in Mathematics and Accounts were computed to determine their relationship and results as follows:

Table 1: Year1 Students Scores in Mathematics and Accounts.

\begin{tabular}{|l|l|l|l|l|l|l|l|l|l|l|}
\hline Mathematics & 4 & 6 & 8 & 10 & 12 & 4 & 6 & 2 & 8 & 4 \\
\hline Accounts & 6 & 8 & 10 & 12 & 14 & 8 & 8 & 10 & 10 & 14 \\
\hline
\end{tabular}

$\mathrm{r}=0.48, \mathrm{df}=16$, critical value $=.74, \mathrm{P}>.05$

In Table one above, the correlation between the two variables (mathematics and Accounts) was 0.48. The correlation was low and was not statistically significant at 0.05 levels.

Table 2: Year 2 Student's scores in Mathematics and Accounts.

\begin{tabular}{|l|l|l|l|l|l|l|l|l|l|l|}
\hline Mathematics & 6 & 4 & 8 & 4 & 4 & 2 & 6 & 6 & 8 & 2 \\
\hline Accounts & 18 & 10 & 16 & 10 & 8 & 8 & 8 & 12 & 14 & 10 \\
\hline
\end{tabular}

$\mathrm{r}=0.67, \mathrm{df}=16$, critical value $=.74, \mathrm{P}>.05$

In Table 2 above, the correlation between the two variables (mathematics and Accounts) was 0.67. The correlation was not found to be statistically significant at 0.05 levels.

Table 3: Year 3 Students Scores in Mathematics and Accounts.

\begin{tabular}{|l|l|l|l|l|l|l|l|l|l|l|}
\hline Mathematics & 6 & 4 & 8 & 4 & 4 & 2 & 6 & 6 & 2 & 6 \\
\hline Accounts & 18 & 10 & 16 & 10 & 8 & 8 & 8 & 8 & 14 & 10 \\
\hline
\end{tabular}

$\mathrm{r}=0.40, \mathrm{df}=16$, critical value $=.74, \mathrm{P}>.05$

In Table 3 above, the correlation between the two variables (mathematics and Accounts) was 0.40. The correlation was not found to be statistically significant at 0.05 levels.

Table 4: Year 4 Students Scores in Mathematics and Accounts.

\begin{tabular}{|l|l|l|l|l|l|l|l|l|l|l|}
\hline Mathematics & 6 & 4 & 4 & 4 & 4 & 4 & 6 & 8 & 6 & 4 \\
\hline Accounts & 16 & 16 & 16 & 14 & 12 & 8 & 12 & 8 & 6 & 12 \\
\hline
\end{tabular}

$\mathrm{r}=0.11, \mathrm{df}=16$, critical value $=.74, \mathrm{P}>.05$

In Table 4 above, the correlation between the two variables (mathematics and Accounts) was 0.11. The correlation was not found to be statistically significant at 0.05 levels. 
IV. Interpretation of Data

The Data in table 1, 2 and 4 revealed that was a positive relationship between the test performances in Mathematics and Accounts. The relationship was not statistically significant although it showed some relatively linear relationship between the two variables; still the relationship was not statistically significant.

It therefore could be inferred that students can enroll for Accounting without necessarily being so outstanding in Mathematics.

\section{Summary, Conclusion and Recommendation}

From the analysis so far, it can be inferred that students who are not exceptionally knowledgeable in mathematics can conveniently pursue a degree course in Accounting. As it was said at the beginning, that there is no scientific evidence to support or dispute the claim that only exceptionally brilliant students who are well grounded in mathematics can undertake a degree program in Accountancy and other courses that involves high level calculations The impression that only exceptionally brilliant students who have background knowledge in mathematics can undertake a degree course in Accounting, has discouraged the prospective students from enrolling into the department to pursue a degree course. This notion has lured many prospective students to go for other courses which according to them involve little or no calculations. This uninformed decision according to Sambo, (2005) can likely lead to dissatisfaction and under achievement since they will be lured to pursue other courses which are contrary to what they desired in life.

The following recommendations are therefore put forward for the purpose of this study;

1. Motivations should be given to students so as to encourage them to work at their own pace and not to be threatened or intimidated by the performances of exceptionally brilliant students.

2. Admission requirements into degree programs in Accountancy should include a fundamental knowledge in Accounting and other business oriented related subjects.

3. Accountancy and Business Education teachers should be friendly, approachable and motivating so as to develop the interest of prospective students in that field of endeavour.

4. Accountancy and Business Education teachers should equip themselves with the knowledge in the emerging areas in the field by attending conferences, seminars, reading related books and articles and inculcating same in the students.

5. Students who possess little or no background knowledge in Mathematics should not be deterred or discouraged to enroll in Accountancy, since they have greater chances of copping if only they can concentrate and get focused in their preliminary years of study.

\section{References}

[1]. Amaewhule, W. (2003). Nigerian Entrepreneur and the School-Industry Based Education. A Paper Presented at the Annual Conference of Nigeria Vocational Association held in University of Uyo, Akwa- Ibom State $8-11^{\text {th }}$ December.

[2]. Nwaobuna, E.C (2004), Information Technology (IT) and Enhancement of Entrepreneurship Education in Secretarial Studies Program in Polytechnics in Nigeria. A Paper Presented at the Association of Business Educators UNICAL Calabar. $2^{\text {nd }}-6^{\text {th }}$ November.

[3]. Nwobasi, P.A. (2007). Correlation Study Between Performances in Physics, Mathematics and Mechanical / Metal Works among Undergraduate (Industrial) Technology Students. Ebonyi Journal of Business Education.1 (1).

[4]. Nzelibe, E.C. (2006). Entrepreneurship and Management of Small Scale Business. Enugu: Optima Publishers.

[5]. Oborah J.O (2006) Business Education and Entrepreneurial Development .A Survey of Enterprise Opportunities. Business Education Journal. 1 (2): 34-38.

[6]. Olaitan, S.O. (1996). Vocational and Technical Education in Nigeria: (Issues and Analysis), Onitsha: Nobel graphics.

[7]. Osuala, E.G. (2004). Principles and Practices of Small Scale Business Management in Nigeria. A Didactic Approach. Nigeria: Fulladu Publishing Company.

[8]. Sambo, B.I (2005). "Effectiveness of Self Fulfilling Prophesy on Students Performance. Nigeria Teacher Today. Vol.4. No.1, October, PP 191-198.

[9]. Nwaokolo P. O. E. (2003). Related thoughts in Vocational Education: The Developing world Experience. Onitsha Stan (Nig) co, printing and publishing.

[10]. Obasi E. (1998). Education and Employed in Nigeria. An Agenda for a New Paradigm. Ogwashi UKX Bendel, Nigeria, Martin Industrial Press and Publishing Company.

[11]. Ojo, K.E and Gbinigie, O. (2006) Entrepreneurship Development as a Tool for Tackling Youths Unemployment in Nigeria: Issues and Strategies. Association of Business Education of Nigeria Book of Reading, vol. 1(6): 181- 192.

[12]. Osuala E.C (2004). Principles and Practice of Small Business Management in Nigeria. Nsukka: Fulladu Publishers Company.

[13]. Otite O (1990). Ethnic Pluralism and Ethnicity in Nigeria. Ibadan, Shaneson.

[14]. Shawulu R. (2000). The Socio Economic and Political Context of Ethnic and Religious Crises in Nigeria" in Okoye, F (Ed.), Impact of Religious and Ethnic Conflict on Women and Children in Northern Nigeria. Kaduna, Human Rights Monitor.

[15]. Okafor F.U (1997). New Strategies for Curbing Ethnic and Religious Crisis in Nigeria. Enugu, Fourth Edition Publishers.

[16]. Okoye F. (2000). Impact of Religious and Ethnic Conflicts on Women and Children in the Northern Nigeria. Kaduna, Human Rights Monitor. 